Journal of Engineering and Applied Sciences 14 (15): 5143-5151, 2019

ISSN: 1816-949X

(C) Medwell Journals, 2019

\title{
The Efficiency of Cluster Barrier Building Organization in Reducing Traffic Noise in the Built Area
}

\author{
Hanan M. Ahmad \\ Department of Architecture, Faculty of Architecture and Design, \\ Middle East University, Amman, Jordan \\ hm.jumaily@gmail.com
}

\begin{abstract}
This paper studies the effect of barrier building organization and noise receiving point locations relative to a street (source line) on traffic noise attenuation between the buildings in the built area facing busy street which is considered as (linear finite-length sound sources). The objective of the research is to study the variables affecting the attenuation values of traffic noise in receiving points between and behind the buildings in an urban environment overlooking busy streets. A theoretical background of sound wave penetration between buildings facing streets in general is presented. In addition to study, the variables affecting noise attenuation behind groups of barrier buildings. Mathematical models have been proposed to calculate the traffic noise attenuation values in different receiving points located between and behind barrier buildings facing traffic noise. Computer simulation of three types of cluster barrier buildings, each type consist of two case studies with different receiving point locations relative to street are studied to explain the effect of different building organization types the ratio of gaps in barrier buildings and its distances from the street (source line) on noise waves penetration to the built area. Results of this study indicate that the form of cluster building type, its location, direction and receiving point location affects the exposure degree of the receiving points to the noise source line behind these building which in turn affects traffic noise attenuation values. It is concluded that the solidity form of some cluster building and its distance far from the first row of barrier buildings will increase the traffic noise attenuation values in built area behind barrier buildings.
\end{abstract}

Key words: Traffic noise, noise attenuation, sustainable urban planning, barrier building, urban acoustical environment, environmental noise pollution

\section{INTRODUCTION}

The soundscape is seen as an integral part of any urban environment when planning areas or subdivision of land located near busy streets. Noise pollution sources should be considered at the master planning and concept planning stage. There is close relation between traffic noise control and the planning of the city in particular when planning new developments in building areas and streets. In other words, traffic noise control is closely related to urban planning. The noise levels are high near busy streets and low in shielded areas or areas far from busy streets. Thus, the traffic noise levels are related to the local traffic volumes. The traffic volumes are in turn closely related to the infrastructure of the city in particular to the road network and the buildings. Thus, we have a two-stage relation from infrastructure to traffic noise (Anonymous, 2012):

- Buildings and road network influence traffic volumes

- Traffic volumes determine traffic noise levels in particular traffic noise levels at the houses of the inhabitants
Noise levels at the façade of a building depend on the distance to the street and on the traffic volume. Closed building blocks lead to lower noise levels at facades that are not exposed directly to traffic noise (quiet facades) (Salomons and Pont, 2012).

Buildings facing busy streets act as a barrier block forming a buffer zone between the noise source (traffic noise) and the receiver built environment. So, it is considered as an urban design element that must be consistent and integrated with the design treatments. These buildings do not block the source completely allowing for gaps in between. These gaps are considered as paths for noise wave penetration to the area to be protected (Anonymous, 2012).

As stated above hypothesis is formulated as follow: "The configuration of cluster buildings facing busy street affect the locations of traffic noise receiving points which in turn influence the noise attenuation in this built area".

\section{MATERIALS AND METHODS}

Cluster barrier buildings: The organization of barrier buildings with respect to the street's location and 


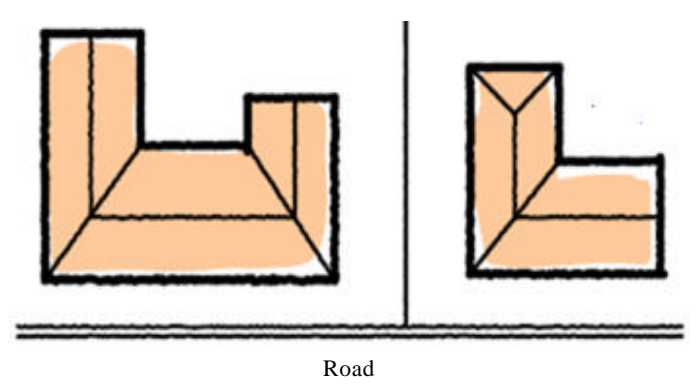

Fig. 1: The layout of cluster barrier building

different exposure degrees of the noise receiving points in open spaces between and behind those barrier buildings to the street will affect the value of noise attenuation. The variables affecting noise attenuation in buildings organization (like cluster buildings) surrounding open spaces are:

- Spreading of direct sound waves through the gaps between the buildings and reflected sound wave paths between building's facades (Anonymous, 2008)

- Clustered building's orientation degree with respect to the street's direction

- The number of gaps between barrier buildings that interrupt barrier continuity to allow noise waves to penetrate the built area

- The distance between buildings in the same cluster grouping

- $\quad$ Staggering building which will provide acoustical shadow area behind buildings (Anonymous, 2012)

- The impact of articulated buildings on sound waves reflection to other buildings (Anonymous, 2008)

Acoustics site planning involves the careful arrangement of buildings on site, so as to minimize the effect of traffic noise (Anonymous, 2003a, b). The impact of traffic noise can be reduced in several ways:

- Increasing the distance between the street and the built area

- Building orientation and its location away from the facade exposed to the noise source

- Using buildings in ' $U$ ' or ' $L$ ' shaped layout to create sheltered outdoor recreation areas

- $\quad$ Protected from noise (Fig. 1) (Anonymous, 2012)

Computer simulation of mathematical models: Mathematical models are used to represent three types of sound barrier clustered building layouts. Each type of cluster grouping considers two case studies which are as follows. Clustered buildings surrounding an open space parallel to the source line in one row as shown in Fig. 2. Locating the receiving points $(\mathrm{A}, \mathrm{B})$ on one line away $20 \mathrm{~m}$ from the source line for the first case studies $(1,2,3)$.

Recessed (retracted) middle cluster buildings to increase the distance between the street and the receiving points (A, B), setting their distance from the source line for the second case studies (1-3a) to $20 \mathrm{~m}$ for side cluster buildings and $30 \mathrm{~m}$ for middle cluster buildings. The location of the receiving points (A) and (B) were in two position:

- Receiving points (A) located behind the barrier building

- $\quad$ Receiving points (B) located in front of the building gap

The measuring network of the mathematical simulation models is three dimensional ( $\mathrm{x}, \mathrm{y}$ and $\mathrm{z}$ ). The $\mathrm{x}$ axis is the set of point sources equal in distance from each other (source line). The $\mathrm{z}$ axis is the source line height $(0.5 \mathrm{~m})$. The $\mathrm{y}$ axis represents the different distances between the receiving points and the source line which varied between the two case studies of each type (Fig. 2).

\section{Hypothesis constants:}

- The distance of the receiving points from the barrier building is $1 \mathrm{~m}$

- The value of the sound pressure level assumed at the street $\left(\mathrm{L}_{\mathrm{p}}\right)$ is $75 \mathrm{~dB}$

- The height of the receiving point from the ground is $0.5 \mathrm{~m}$

\section{Hypothesis variables (parameters):}

- The length of the visual linear source $(\mathrm{dx})$ from the receiving point

- The values of the visual angle of the source from the receiving points $(\boldsymbol{\theta})$

- $\quad$ The Opening Factor value $(\mathrm{OF})$

- The location of receiving points $(\mathrm{X}, \mathrm{Y})$ axis

- The arrangement of cluster building groups relative to source line (road)

- The distance between source line (road) and the receiving points for middle cluster buildings (second case studies $(1-3 a)$

Figure 2 shows the effect of cluster building's types of the mathematical model with different exposure degrees of noise on the visual angles of receiving points. 

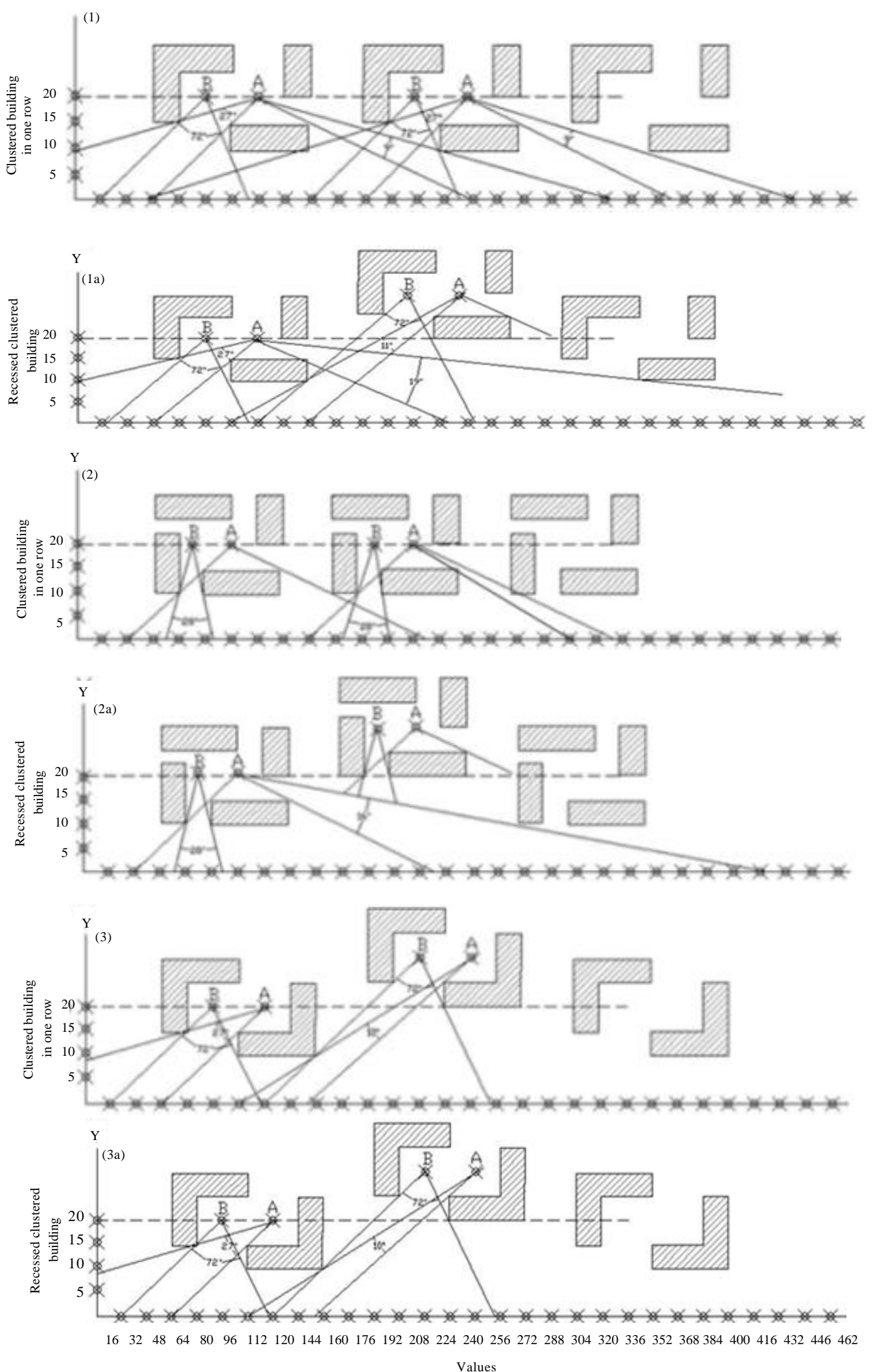

Fig. 2: Mathematical models shows the types of cluster building groups 


\begin{tabular}{|c|c|c|c|c|c|}
\hline Type of case studies & $\begin{array}{c}\text { Building cluster location/ } \\
\text { Receiving points }\end{array}$ & $\begin{array}{l}\text { Visual angles } \\
\text { value }(\theta)\end{array}$ & $\begin{array}{l}\text { Visual length of } \\
\text { linear source }(\mathrm{dx}) \mathrm{m}\end{array}$ & $\begin{array}{l}\text { Average gap } \\
\text { length (m) }\end{array}$ & $\begin{array}{c}\text { Average barrier } \\
\text { length (m) }\end{array}$ \\
\hline \multirow[t]{6}{*}{1} & Side cluster & & & & \\
\hline & A & $27(9)$ & $128(96)$ & 68.8 & 32 \\
\hline & B & 72 & 96 & & \\
\hline & Middle cluster & & & & \\
\hline & A & $27(9)$ & $128(96)$ & & \\
\hline & B & 72 & 96 & & \\
\hline \multirow[t]{6}{*}{ 1a } & Side cluster & & & & \\
\hline & A & $27(19)$ & $128(272)$ & 96.0 & 32 \\
\hline & B & 72 & 96.0 & & \\
\hline & Middle cluster & & & & \\
\hline & A & $11(0)$ & $48(0)$ & & \\
\hline & $\mathrm{B}$ & 72 & 144 & & \\
\hline \multirow[t]{6}{*}{2} & Side cluster & & & & \\
\hline & A & $0(0)$ & $0(0)$ & 22.4 & 32 \\
\hline & $\mathrm{B}$ & 28 & 32 & & \\
\hline & Middle cluster & & & & \\
\hline & A & $0(10)$ & $0(44)$ & & \\
\hline & B & 28 & 32 & & \\
\hline \multirow[t]{6}{*}{$2 a$} & Side cluster & & & & \\
\hline & A & $0(16)$ & $0(196)$ & 57.6 & 32 \\
\hline & B & 28 & 32 & & \\
\hline & Middle cluster & & & & \\
\hline & A & $0(0)$ & $0(0)$ & & \\
\hline & B & 28 & 48.0 & & \\
\hline \multirow[t]{6}{*}{3} & Side cluster & & & & \\
\hline & A & $27(0)$ & $152(0)$ & 48.0 & 32 \\
\hline & B & 72 & 96 & & \\
\hline & Middle cluster & & & & \\
\hline & A & $26(0)$ & $128(0)$ & & \\
\hline & B & 72 & 96 & & \\
\hline \multirow[t]{6}{*}{$3 a$} & Side cluster & & & & \\
\hline & A & $27(0)$ & $152(0)$ & 128.0 & 32 \\
\hline & B & 72 & 96 & & \\
\hline & Middle cluster & & & & \\
\hline & A & $10(0)$ & $44(0)$ & & \\
\hline & B & 72 & 144 & & \\
\hline
\end{tabular}

Calculation of parameter values using geometrical analysis of models:

- Coordinates of point sources that constitute the finite linear source by visual angles at different reception points (A, B)

- Coordinates of noise reception points (A, behind the building; $\mathrm{B}$, in the buildings gap)

- Determine the visual angles from each receiving point to the source line. Two visual angles at the receiving point (A) and one visual angle at receiving point (B)

- Calculate the length of visual linear source $(\mathrm{dx})$ from each receiving point

- Calculate the average buildings barrier lengths

- Calculate the average buildings gap lengths

The parameter values calculated from geometrical analysis of mathematical models the value of visual angles, visual length of linear, average gap length, average barrier length in receiving points (A) (B) in the side and middle building cluster, shown in Table 1.

Application of mathematical equation: The values of parameters resulting from the geometrical analysis of the mathematical models of barrier buildings are used to calculate the attenuation value at each receiving point by using the following equations. The correction factor values (the factors (positive or negative) that will be added to the source sound level which is measured at the source line (street)) can be calculated using the equations below to find the noise level attenuation at the receiving points by using the calculation prediction method. The visual angles attenuation (HM Stationery Office, 1988):

$$
\mathrm{Cu}=10 \log (\theta / 180)
$$

$\mathrm{Cu}=$ Visual angle attenuation for each visual part of source line

$\theta=$ Visual angle

The total visual angles attenuation in receiving point (Att. 6) (Templeton and Saunders, 1987):

$$
\text { Att. } \theta=\sum\left[10^{\text {cul110 }}+10^{\text {cu2110 }}-10^{\text {cu3110 }}+, \ldots\right]
$$

The attenuation value of the visual length of the linear source (HM Stationary Office, 1988):

$$
\mathrm{dx}=\mathrm{X}_{2}-\mathrm{X}_{1}
$$


Where:

$\mathrm{dx}=$ The length of visual linear source

$\mathrm{X}_{1}=$ The first visual point of the linear source from the receiving point

$\mathrm{X}_{2}=$ The last visual point of the linear source from the receiving point

$$
\mathrm{AT} \cdot(\mathrm{dx})=10 \log \left(\mathrm{y} \cdot \mathrm{d}_{\mathrm{z}}\right)
$$

AT $=$ The noise Attenuation value of the visual length of the linear source

$\mathrm{y}=$ The distance between the linear source and the receiving points, $20 \mathrm{~m}$ for the cluster building case studies $(1,2,3), 30 \mathrm{~m}$ for the cluster building case studies (1-3a)
The value of the building's gap factor for the barrier building's gap (O' Flaherty, 1986):

$$
\text { B.G. }=\mathrm{R} /(\mathrm{R}+\mathrm{b})
$$

Where:

B.G. = Building's Gap factor

$\mathrm{R} \quad=$ Average length of building's gap

$\mathrm{b}=$ Average length of barrier building

Table 2 clarifies how the parameter values the length of the visual linear source, the visual angles to the street at reception point (A), (B) and the building gaps length affect the total attenuation value at reception points. Table 3 clarifies how the values of building gaps affect the total attenuation at receiving point

Table 2: The attenuation values of calculated parameters at receiving points Case studies/Cluster building location Receiving points Visual angles attenuation $(\mathrm{dB})$ Visual source attenuation $(\mathrm{dB}) \quad$-.---Total attenuation $(\mathrm{dB})$-----. 1

$1 \mathrm{a}$

$\begin{array}{lr}\text { Side } & -3.2 \\ \text { A } & -8.0 \\ & 0.9 \\ \text { B } & \\ \text { Middle } & -3.26 \\ \text { A } & -8.04 \\ \text { B } & 0.9\end{array}$

-3.26
-8.04
0.99
-3.26
-8.04
0.99

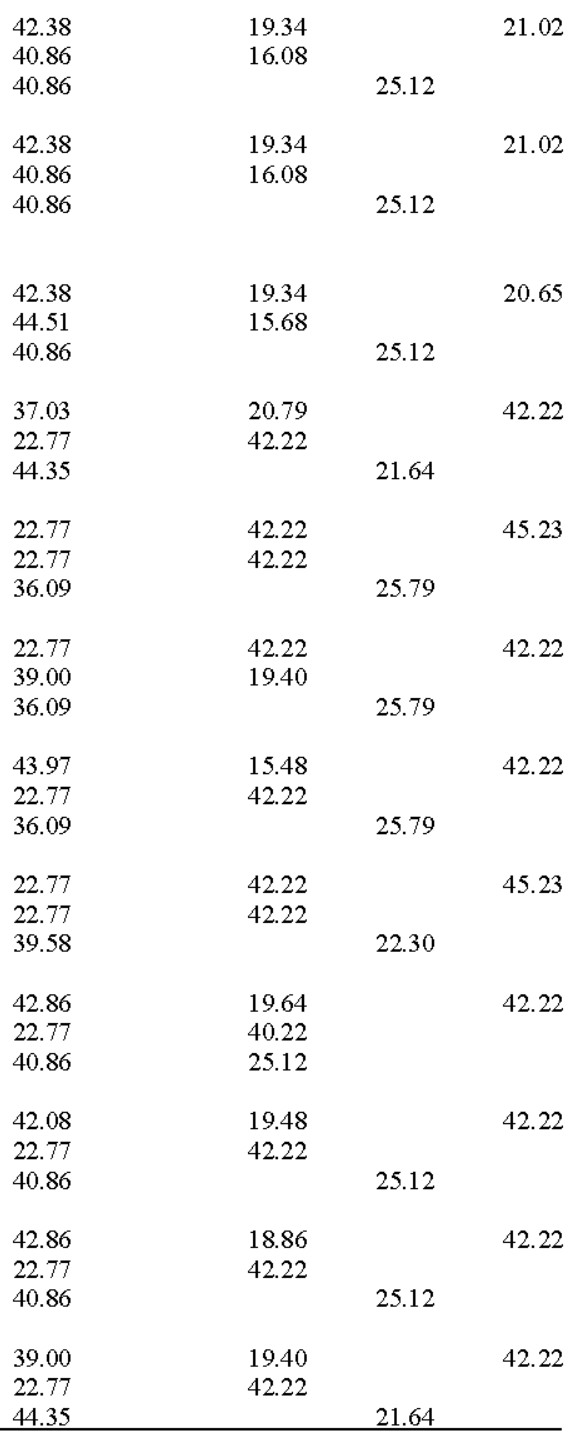


Table 3: The effect of building gaps on total attenuation value at receiving points

\begin{tabular}{|c|c|c|c|c|c|c|c|}
\hline \multirow[b]{2}{*}{ Case studies } & \multicolumn{2}{|c|}{$\begin{array}{l}\text { Total attenuation at } \\
\text { point } A(A t t . A)(d B)\end{array}$} & \multicolumn{2}{|c|}{$\begin{array}{l}\text { Total attenuation at point } \\
\text { B (Att.B) (dB) }\end{array}$} & \multicolumn{3}{|c|}{$\begin{array}{l}\text { The deference in attenuation values } \\
\text { between } A(d A t t . A) \text { and } B(d A t t . B)(d B)\end{array}$} \\
\hline & $\begin{array}{l}\text { Side cluster } \\
\text { buildings }\end{array}$ & $\begin{array}{c}\text { Middle cluster } \\
\text { buildings }\end{array}$ & $\begin{array}{l}\text { Side cluster } \\
\text { buildings }\end{array}$ & $\begin{array}{c}\text { Middle cluster } \\
\text { buildings }\end{array}$ & $\begin{array}{c}\text { Side cluster } \\
\text { buildings }\end{array}$ & $\begin{array}{c}\text { Middle cluster } \\
\text { buildings }\end{array}$ & $\begin{array}{l}\text { Buildings Gap } \\
\text { factor (B.G.) }\end{array}$ \\
\hline 1 & 21.02 & 21.02 & 25.12 & 25.12 & 4.100 & 4.14 & 0.68 \\
\hline $1 \mathrm{a}$ & 20.65 & 42.22 & 25.12 & 21.64 & 4.470 & 20.55 & 0.72 \\
\hline 2 & 45.23 & 42.22 & 25.79 & 25.79 & 19.440 & 19.44 & 0.42 \\
\hline $2 a$ & 42.22 & 45.23 & 25.79 & 22.30 & 16.430 & 22.93 & 0.64 \\
\hline 3 & 42.22 & 42.22 & 25.12 & 25.12 & 17.100 & 17.10 & 0.60 \\
\hline $3 \mathrm{a}$ & 42.22 & 42.22 & 25.12 & 21.64 & 17.100 & 20.58 & 0.80 \\
\hline
\end{tabular}

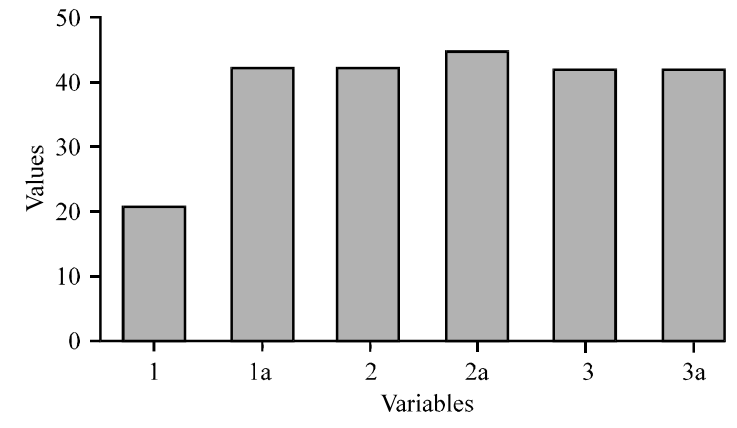

Fig. 3: Comparison between attenuation values at points (A) for middle cluster buildings (Att.A.M)

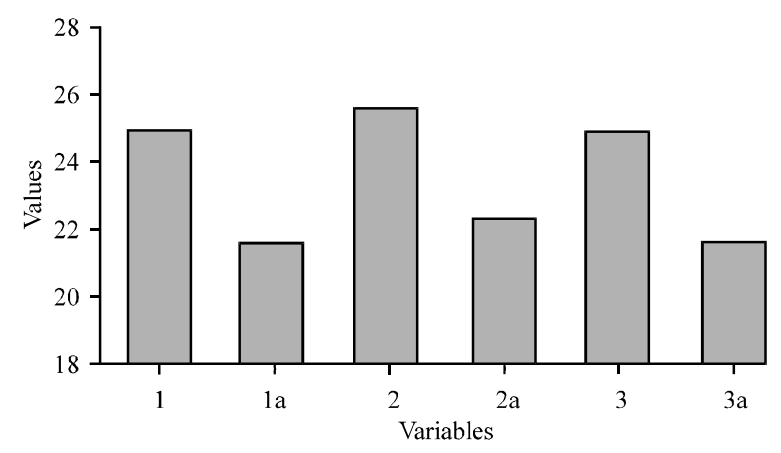

Fig. 4: Comparison between attenuation values at points (B) for middle cluster buildings (Att.B.M)

$\mathrm{A}, \mathrm{B}$ in each of side and middle cluster building, in addition to the building gaps effect on the deference in attenuation values between the receiving points $\mathrm{A}$ and $\mathrm{B}$.

Diagrammatic representation of results: Figure 3 through 12 represent the outcomes of the computer analysis. The results can be shown in histograms. The histograms above clarify how the length of the visual linear source $(\mathrm{dx})$, the value of visual angles ( $\theta$ ) and the Building Gaps values (B.G.) affect the noise attenuation value at receiving points A, B.

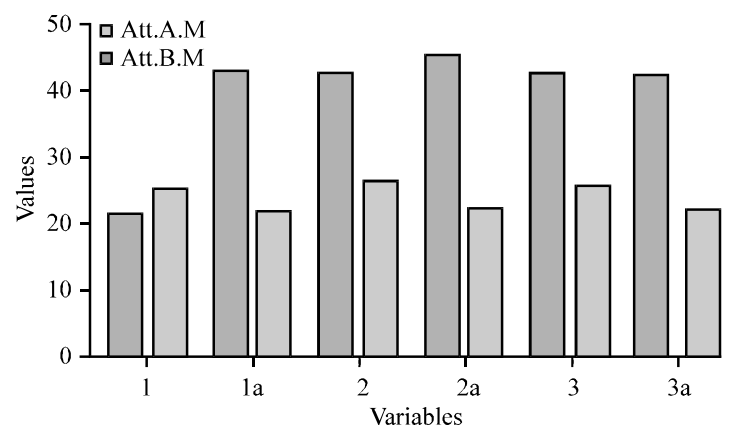

Fig. 5: Comparison between attenuation values at points (A)(Att.A.M), (B)(Att.B.M) for middle cluster building

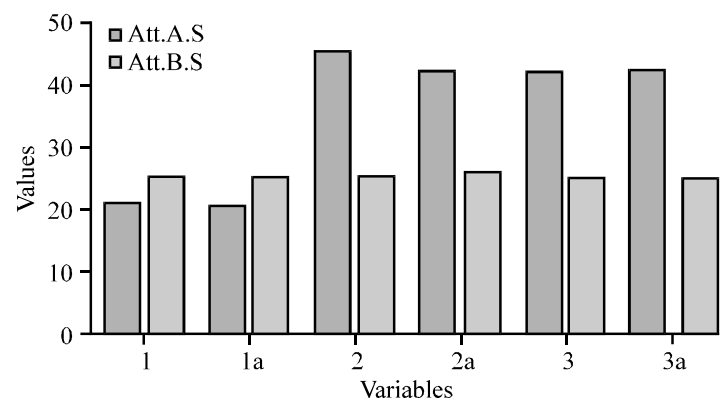

Fig. 6: Comparison between attenuation values at points (A) (Att.A.M), (B) (Att.A.M) for middle cluster buildings

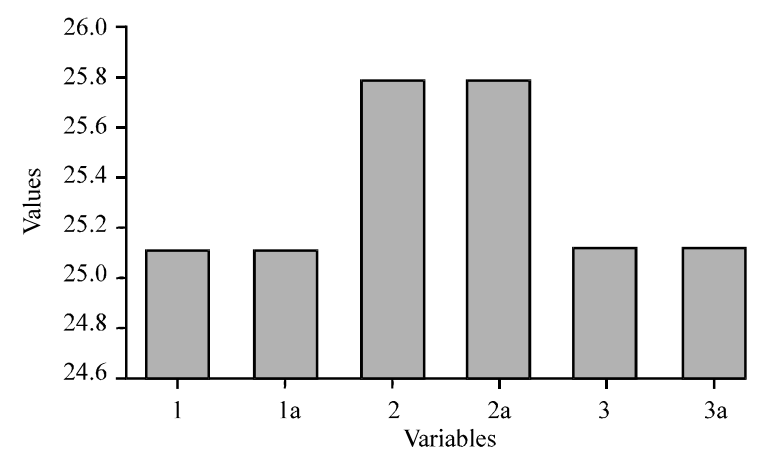

Fig. 7: Comparison between attenuation values at points (B) (Att.B.S) for side cluster buildings 


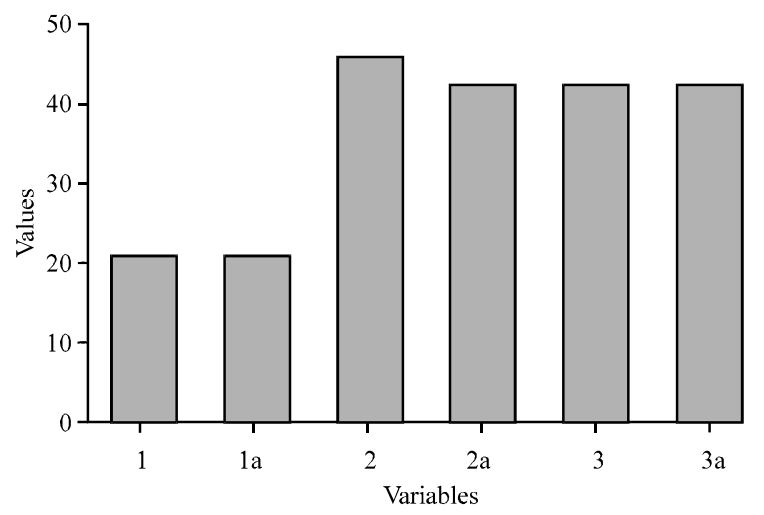

Fig. 8: Comparison between attenuation values at points (A) (Att.A.S) for side cluster buildings

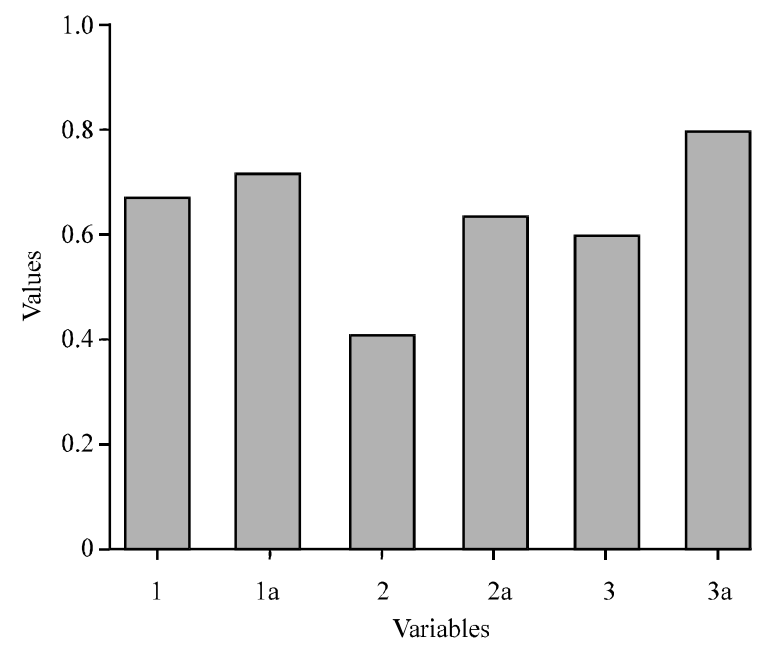

Fig. 9: Comparison between building gaps values for all cluster building types

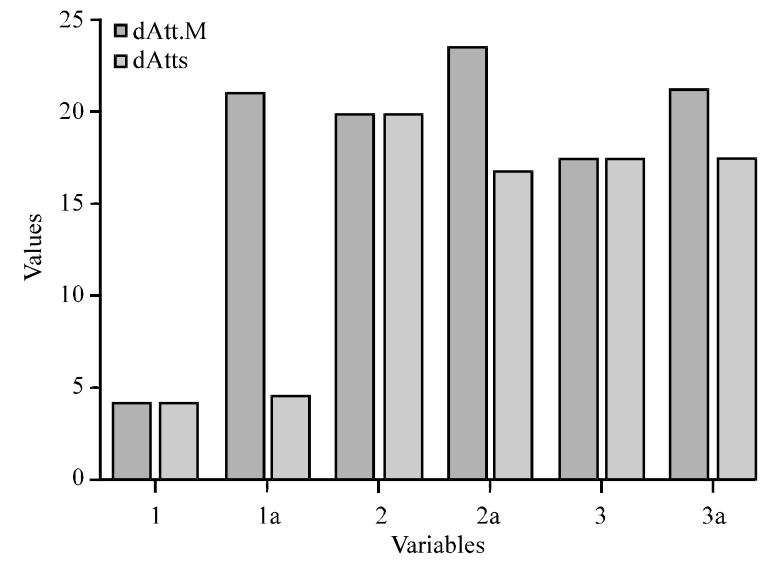

Fig. 10: Comparison the deference in attenuation (B.Gaps) values between receiving points $(\mathrm{A}, \mathrm{B})$ for side cluster buildings (dAtt.s) and middle one (dAtt.M)

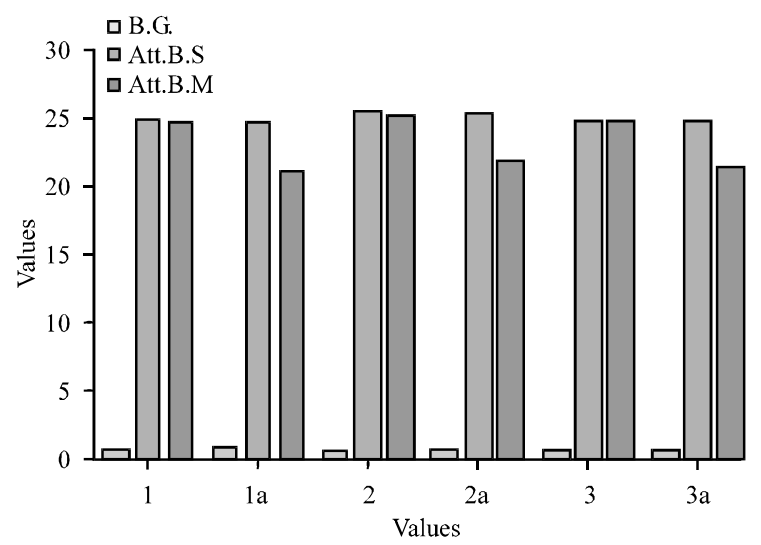

Fig. 11: The effect of Building Gaps (B.G.) on noise attenuation at receiving points $(B)$ in on noise attenuation at reception points (A) in (Att.B.S) and middle cluster (Att.B.M)

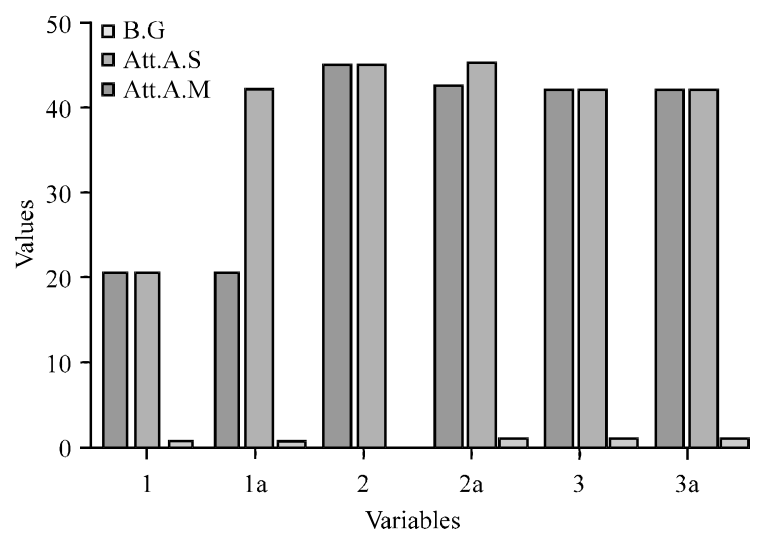

Fig. 12: The effect of Building Gaps (B.G.) side on side attenuation at reception points $(\mathrm{A})$ in side cluster (Att.A.S) and middle cluster (Att.A.M)

\section{RESULTS AND DISCUSSION}

The retreat of middle cluster building in the two case studies (1a) and (2a) lead to increasing the attenuation value at the receiving point (A) More than it was in the study cases (1) and (2). That's due to the change of one or both visual angles value to be $(0)$, the increase of the total visual angles attenuation led to increases the noise attenuation value of that area (Fig. 3).

In case study (3a), the retreat of the middle cluster building doesn't affect the attenuation values of the receiving point (A) of the side cluster building. That is due to mass enclosure of barrier building that surrounds the receiving point (A). Hence, the mass enclosure of the gap-free barrier building increases the sound attenuation more than it was with gaps. The building gaps factor 
increases in case of the retreat of middle cluster buildings because of the increase in building gaps length. That appears clearly when we compare between the two case studies in each type where we notice that decreasing the opening factor increases the attenuation value.

Comparison between the attenuation values at the receiving point $(\mathrm{B})$ in the middle cluster buildings of all case studies shows that the lowest attenuation value was in the case (1a) while the attenuation value at this point increased in the case study (2) to become the highest value because of the difference in each of the values of visual angles and visual source line length due to the different degree of exposure to the source line in both cases (Fig. 4).

It was observed that when comparing the attenuation values of the receiving point (A) in the middle cluster building in all case studies that the lowest attenuation value was in case study (1) and the largest value was in case study (2a) (Fig. 3). This is due to the fact that the two building gaps produce two visual angles observed on the sides of receiving point (A) in the case study (1) which result in increasing their exposure to traffic noise and reducing the attenuation value. It is also noted that this value is increased in both cases ( 2.2 a) due to absence of one or both visual angles (Fig. 5-9).

Comparing the difference in attenuation values between the points (A) and (B) of the side cluster buildings of all types, it was observed that the largest difference in attenuation values between the two points was in the case study (2) and the lowest value was in the case study (1) (Fig. 10).

Comparing the difference in attenuation values between the points (A) and (B) of the middle cluster buildings of all types, it was observed that the largest difference in attenuation values between the two points was in the case study (2a) and the lowest value was in the case study (1) (Fig. 10). Comparing building gap values of the case studies, showed that the smallest building gap was in case (2) and the biggest building gap was in case (3a) (Fig. 9).

The form of the building surrounding the receiving point (A) in the middle cluster building plays a large role in reducing the number of visual angles of the source line, which reduces the degree of its exposure to traffic noise. Therefore, the attenuation value of the gap-free surrounded building (shape L) shown in case study (3), Fig. 2 is greater than its value in case of fragmented surrounding building. This is evident when comparing case study (3) with case study (1). However, the retreat of the middle cluster buildings to the back reduced the degree of exposure of the receiving point to the source line (street) as in cases (2) and (1) because the side cluster buildings provided acoustic shadow to the middle one, which led to absence of visual angles at receiving point (A) as shown in case study (2a) (Fig. 10-14).

Figure 6 shows that there are differences in the attenuation values between the receiving points (A), receiving points $(\mathrm{B})$ in the side cluster buildings. In the while there are convergences of the values of the other hand, it was observed that there are differences in the attenuation values in each of the two points $(A$ and $B)$ in the retreated middle clustered building as shown in Fig. 5.

\section{CONCLUSION}

Traffic noise attenuation reduces by increasing, the value of visual angles at receiving points, the length of the visual line of the sound source and the buildings gaps. This affects building's exposure degree with respect to the street's direction. The largest attenuation value of point (A) in the side cluster buildings was in case study (2) and the lowest value was in case studies 1 and la as shown in figure. The largest attenuation value of the point $(\mathrm{B})$ in the side cluster buildings were in case studies $(2,2 a)$ and the lowest value were in case studies 1 and 3 .

The equality of noise attenuation values between receiving points in both middle cluster building and the side one when they are at the same distance from source line as in the first cases in each building group type (1-3). But in case of the retreat of middle cluster building backwards, the attenuation value increases due to the change of one or two of the visual angles to be $(0)$ which takes the highest calculated attenuation value. That leads to increasing the total attenuation value as shown in figures.

Attenuation value of the visual linear source decreases at point (B) of the retreated middle cluster building in the second case of each type, especially, when it is not located in the acoustical shadow of the adjacent building. That is due to the increase of the visual linear source length when the receiving point (B) gets far from source line which decreases the attenuation value.

The retreat of middle cluster building from the first row of barrier building will affect the visual angle value at the receiving point (A) located behind the barrier building of the side cluster building. Consequently, this will affect the noise attenuation value but this receiving point will 
not be affected when it is surrounded by continues building enclosure even, if these building are equal in distance from the source line as shown in type (3). It is necessary to surround the receiving points with continues building free of gaps to get effaces traffic noise attenuation or to make the receiving points located in the acoustical shadow area of the adjacent cluster buildings. The barrier buildings shall not face the street in one row or the same distance from the street line.

\section{ACKNOWLEDGEMENT}

The researchers would like to appreciate the Deanship of Scientific Research at Middle East University for their support.

\section{REFERENCES}

Anonymous, 2003a. A guide to the reduction of traffic noise. VicRoads Road Services, Ardeer, Australia.

Anonymous, 2003b. Guidelines on design of noise barriers. Highways Department, Environmental Protection Department, Government of the Hong Kong SAR, Hong Kong. https://www .epd. gov.hk/ epd/sites/default/files/epd/english/environmentinhk/ noise/guide_ref/files/barrier_leaflet.pdf
Anonymous, 2008. Development near rail corridors and busy roads-interim guideline. Department of Planning and Environment, New South Wales. https://www.rms.nsw.gov.au/documents/projects/g uideto-infrastructure-development-near-rail-corrido rs-busy-roads.pdf

Anonymous, 2012. Reducing noise and air impacts from road, rail and mixed land use: A guide for builders, designers and the community. Department of Planning, Transport and Infrastructure, South Australia. https://www.sa.gov. au/_data/assets/pdf_file/0016/21391/Design_Guid elines_Reducing_noise_and_air_impacts_from_ro ad_rait_and_mixed_land_use.pdf

HM Stationery Office, 1988 . Calculation of Road Traffic Noise. H.M. Stationery Office, Richmond, UK., ISBN: 9780115508479 , Pages: 95.

O' Flaherty, C.A., 1986. Highways. 3rd Edn./Vol. 1., Traffic Planning and Engineering, USA.,.

Salomons, E.M. and M.B. Pont, 2012. Urban traffic noise and the relation to urban density, form and traffic elasticity. Landscape Urban Plann., 108: 2-16.

Templeton, D. and D. Saunders, 1987. Acoustic Design. Princeton Architectural Press, New York, USA., ISBN:9780851391441, Pages: 152. 